\title{
Сотрудничество НАТО с ООН и ЕС: основные вызовы
}

\author{
Агата Шиделко *
}

Как определить НАТО, когда мы его сравниваем с Объединенными нациями и с Европейским союзом? Является ли НАТО «институцией действия» (ориентированной на выполнение задач) или «институцией существования» (основанной на идентичности)? При попытке определить роль НАТО и причины для его существования в сравнении с Организацией объединенных наций $(\mathrm{OOH})$ и с Европейским союзом (ЕC) и пытаясь ответить на вопрос, является ли НАТО основанной на идентичности или ориентированной на задачи организацией, стоит обратится к источникам и понять в первую очередь, когда и как эти три международные институции были учреждены и что является основным двигателем их процесса принятия решений.

\section{Когда? Создание ООН, ЕС и НАТО}

Организация Объединенных Наций была учреждена 24 октября 1945 года, когда ее Устав был ратифицирован Китаем, Францией, Советским Союзом, Объединенным Королевством и Соединенными Штатами, а также большинством из первых пятидесяти одной стран-членов. День Объединенных Наций отмечается 24 октября каждого года.

Организация Северо-Атлантического Договора (НАТО) была основана в Вашингтоне, округ Колумбия, 4 апреля 1949 года. Договор, подписанный министрами иностранных дел Бельгии, Великобритании, Канады, Дании, Франции, Исландии, Италии, Нидерландов, Норвегии, Португалии и Соединенных Штатов, обеспечивал взаимную помощь в случае нападения на страну-члена союза. Греция и Турция присоединились к НАТО 18 февраля 1952, а Федеральная Республика Германия (Западная Германия) - 9 мая 1955, таким образом сформировав начальный состав Альянса из 14 членующих государств.

Агата Шиделко работает главным бизнес-менеджером, ответственным за стратегическое планирование, развитие сотрудничества и контроль финансово-хозяйственной деятельности при поддержке многонационального и двухстороннего сотрудничества со странами в области C4ISR в Директорате Спонсорских Программ НATO и Партнеров (ДСП НП) в С3 агенции НАТО. Этот доклад был разработан в рамках 2011-2012 года курса Программы усовершенствования администраторов НАТО (ПУАН), осуществляемой ЕSCP Европейской Бизнес Школой под руководством др. Кристины Барриос. ПУАН - это престижная девятимесячная программа, предназначенная конкретно для гражданских менеджеров НАТО среднего и верхнего уровня. Целью программы является установление и развитие во всех странах Альянса сети из гражданских администраторов международного уровня, отличающихся талантом и потенциалом. Программа расширяет их знания о НАТО, о его идентичности и основных ценностях, а также дает углубленное понимание быстро меняющегося мира.

Мнения, выраженные в этой работе, отражают только авторскую точку зрения и могут не совпадать с официальной позицией NC3A, НАТО и стран-членов. 
Примерно через год после основания НАТО, 9 мая 1950, Роберт Шуман, французский министр иностранных дел, произнес важную речь, выдвинув предложения, основанные на идеях Жана Моне. Он предложил, чтобы Франция и Федеральная Республика Германия соединили свои ресурсы угля и стали и образовали новую организацию, к которой могли присоединяться и другие европейские страны. Эта дата считается днем рождения Европейского Союза, и 9-ое мая теперь отмечается ежегодно как День Европы. 18 апреля 1951 шесть стран - Бельгия, Федеральная Республика Германия, Франция, Италия, Люксембург и Нидерланды подписали договор, учредивший Европейское Сообщество Угля и Стали (ЕСУС). Так в течении менее чем десяти лет-с 1945 по 1955-европейские страны, страны с самой длинной историей вооруженных конфликтов за последние несколько веков, и которые в течении предшествовавших тридцати лет воевали друг против друга в двух мировых войнах, решили совместно учредить и/или принять участие в трех международных институциях, каждая из которых имела ясный фокус на утверждение сотрудничества и направления коллективных усилий на развитие международного мира и прав человека.

\section{Почему? Причины для основания ООН, ЕС и НАТО}

Первоначальные причины для учреждения этих трех институций описаны соответственно в их основных документах: Уставе Объединенных наций, Североатлантическом договоре и Уставе Совета Европы, и могут быть обобщены в сравнительной таблице, приведенной ниже. ${ }^{1}$

Хотя реализация ценностей развивалась во времени, основные ценности остались по сути неизменными в течении более шестидесяти лет существования соответствующих организаций. Эти шесть десятилетий, однако, не прошли без изменений. Европейский Союз ратифицировал семь последовательных договоров с 1949 Рим (1957), Мергер (1965), Шенген (1985), Ницца (2001), Маастрихт (1992), Амстердам (1997) и Лиссабон (2007), тогда как НАТО приняло семь Стратегических концепций со дня основания Альянса.

При попытке отличить основные принципы НАТО от основных принципов ООН и ЕС, самое четкое отличие видно в дефиниции причин для существования НАТО. Ссылка на базовые ценности мира и свободы (дополненных демократией и индивидуальной свободой) относится напрямую к конкретным политическим системам,

1 Статут Совета Европы доступен на http://conventions.coe.int/Treaty/Commun/QueVoulez Vous.asp?NT=001\&CM=8\&DF=26/12/2011\&CL=ENG. Глава 1, Параграф 1 статута декларирует, что «Целью Совета Европы является достижение большего единства между его членами для защиты и реализации идеалов и принципов, которые являются их общим наследством, и содействовать их экономическому и социальному прогрессу». Далее объясняется, что «Следование этой цели будет осуществляться органами Совета путем обсуждения вопросов, представляющих взаимный интерес, соглашениями и общими действиями в экономических, социальных, правовых, культурных, научных и административных вопросах и поддержании и дальнейшей реализации фундаментальных свобод и прав человека». 
Таблица 1: Первоначальные причины для учреждения ООН, ЕС и НАТО.

\begin{tabular}{|c|c|c|c|}
\hline & $\begin{array}{c}\text { Объединенные нации: } \\
\text { Устав Объединенных } \\
\text { наций (1945) }\end{array}$ & $\begin{array}{l}\text { НАТО: Севе- } \\
\text { роатланти- } \\
\text { ческий дого- } \\
\text { вор (1949) }\end{array}$ & $\begin{array}{c}\text { ЕС: Устав Совета } \\
\text { Eвponbl (1949) }\end{array}$ \\
\hline Ценности & $\begin{array}{l}\text { Международный мир и } \\
\text { безопасность, признание } \\
\text { принципа равных прав и } \\
\text { самоопределения наро- } \\
\text { дов }\end{array}$ & $\begin{array}{l}\text { Мир, свобода, } \\
\text { демократия, } \\
\text { индивидуаль- } \\
\text { ные свободы }\end{array}$ & $\begin{array}{l}\text { Идеалы и принципы, } \\
\text { являющиеся общим на- } \\
\text { следством стран-чле- } \\
\text { нов; права человека и } \\
\text { фундаментальные сво- } \\
\text { боды }\end{array}$ \\
\hline Цели & $\begin{array}{l}\text { Развивать дружеские } \\
\text { отношения; продвигать и } \\
\text { поощрять уважение к } \\
\text { правам человека и к } \\
\text { фундаментальным сво- } \\
\text { бодам; служить центром } \\
\text { для гармонизации } \\
\text { действий отдельных } \\
\text { наций для достижения } \\
\text { этих общих целей }\end{array}$ & $\begin{array}{l}\text { Верховенство } \\
\text { закона, ста- } \\
\text { бильность, } \\
\text { благоденствие }\end{array}$ & $\begin{array}{l}\text { Достижение большего } \\
\text { единства между его } \\
\text { членами }\end{array}$ \\
\hline Задачи & $\begin{array}{l}\text { Предпринимать эффек- } \\
\text { тивные коллективные } \\
\text { меры (и другие соответ- } \\
\text { ствующие меры) для ук- } \\
\text { репления универсального } \\
\text { мира и достижения меж- } \\
\text { дународного сотрудни- } \\
\text { чества в решении меж- } \\
\text { дународных проблем } \\
\text { экономического, соци- } \\
\text { ального, культурного или } \\
\text { гуманитарного характера }\end{array}$ & $\begin{array}{l}\text { Обеспечение } \\
\text { коллективной } \\
\text { обороны и за- } \\
\text { щита мира и } \\
\text { безопасности }\end{array}$ & $\begin{array}{l}\text { Содействовать эконо- } \\
\text { мическому и социаль- } \\
\text { ному прогрессу стран- } \\
\text { членов, служить фору- } \\
\text { мом для дискуссий по } \\
\text { вопросам общих инте- } \\
\text { ресов; предпринимать } \\
\text { соглашения и общие } \\
\text { действия по экономи- } \\
\text { ческим, социальным, } \\
\text { культурным, научным, } \\
\text { правовым и админист- } \\
\text { ративным вопросам и } \\
\text { при дальнейшей реали- } \\
\text { зации прав человека и } \\
\text { основных свобод }\end{array}$ \\
\hline $\begin{array}{l}\text { Географиче- } \\
\text { ские ограни- } \\
\text { чения }\end{array}$ & Нет & $\begin{array}{l}\text { Северо-Атлан- } \\
\text { тический ре- } \\
\text { гион }\end{array}$ & $\begin{array}{l}\text { Европейский конти- } \\
\text { нент (плюс Объеди- } \\
\text { ненное Королевство) }\end{array}$ \\
\hline $\begin{array}{l}\text { Текущее } \\
\text { число стран- } \\
\text { членов }\end{array}$ & 194 & 28 & 27 \\
\hline
\end{tabular}


которые Альянс стремится защитить. Еще в учредительных документах НАТО очень четко определило действительные методы для сохранения этих ценностей, как на уровне установления общей идентичности путем верховенства закона, стабильности и благоденствия, так и на уровне конкретных шагов для сохранения мира и безопасности путем коллективных оборонительных гарантий между государствами-членами.

\section{Как? Принципы принятия решений в ООН, ЕС и НАТО}

Используемые основные принципы принятия решений этими тремя организациями варьируют весьма значительно. Однако, и в трех организациях неизменным элементом процесса принятия решения является подготовка решений до их формального одобрения, так что когда предложения действительно выдвигаются на высочайшем уровне, никаких реальных дискуссий не происходит. Вместо этого решения, которые уже согласованы для принятия, просто официально утверждаются.

Новая система ЕС-голосования с квалифицированным большинством в наибольшей степени похожа на действительные политические практики установившихся европейских демократий. Квалифицированное большинство достигается, только если решение поддерживается 55 процентами стран-членов, включая как минимум 15 из них; нации в группе большинства должны представлять не меньше 65 процентов населения Союза. ${ }^{2}$ Хотя решения только в определенных областях политики остаются принимаемыми консенсусом полностью или частично, в действительности Совет пытается достигнуть единодушных решений и голосование квалифицированным большинством часто используется как средство нажима на членов для достижения компромисса, необходимого для того, чтобы прийти к консенсусу. К примеру, в 2008 году 128 из 147 решений Европейского Совета были единоглас-

2 Смотри “A New System of Qualified Majority," at http://europa.eu/scadplus/constitution/ doublemajority_en.htm. Статья I-25 Конституционного Договора определяет новую систему голосования квалифицированным большинством. От старой системы, которая распределяла каждой стране-члену определенное число голосов, отказались в пользу системы двойного большинства. Положение, согласно которому квалифицированное большинство должно быть поддержано 55 процентами стран-членов, включая как минимум 15 из них, необходимо пояснить: в союзе из двадцати пяти государств 15 государств составляют 60 процентов из всех. Однако, в союзе из более чем двадцати пяти стран, это положение потеряет свое значение: с того момента, как союз расширится до двадцати шести членов, 55 процентов из общего числа математически будет означать минимум 15 из них. Следовательно, это положение можно рассматривать как переходное.

Статья I-25 указывает, что эти положения также применяются в случаях, когда Европейский Совет принимает решения квалифицированным большинством, при этом Президент Европейского Совета и Председатель Комиссии не участвуют в голосовании. Новая система вошла в силу 1 ноября 2009, дата, когда новая Комиссия прошла инаугурацию после европейских выборов 2009 года. 
ными. При принятии остальных решений в целом было 32 воздержавшихся и только восемь голосов против соответствующего решения. ${ }^{3}$

Европейский Парламент является единственным выбираемым напрямую органом Европейского Союза. Избиратели всех стран-членов Европейского союза составляют 500 миллионов человек и выбирают 736 членов Парламента каждые пять лет. Это означает, что члены Парламента составляют 0.0001472 процентов всего населения ЕС. Это представительство в семь раз меньше среднего отношения для четырех самых больших стран ЕС - Германии: 0.0007585 процента (622 места, 82 миллиона населения); Франции: 0.0009159 процента (577 мест, 63 миллиона населения); Объединенного Королевства: 0.0010484 процента (650 мест, 62 миллиона населения); и Италии (630 мест, 60 миллионов населения). Это также означает, что каждый голос в Европейском Парламенте представляет приблизительно 680000 европейских граждан. Так как места распределены между государствами пропорционально населению, четыре самые большие нации в ЕС-Германия, Франция, Италия и Объединенное Королевство-вместе составляют 43 процента всего парламента.

Система принятия решений, используемая Объединенными Нациями, похоже, представляет полную противоположность принципам европейской демократии. Из 194 стран-членов только пятнадцать представлены в Совете Безопасности ООН. Из этих пятнадцати пять являются постоянными членами: Китайская Народная республика, Франция, Русская Федерация, Объединенное Королевство Великобритании и Северной Ирландии и Соединенные Штаты Америки; непостоянные члены выбираются на два года. Решения Совета Безопасности по процедурным вопросам

3 Определенные области политики остаются подчинены принципу единогласия полностью или частично:

- Членство в Союзе (открытие процедуры переговоров, ассоциирование, серьезные нарушения ценностей Союза и т.д.);

- Налогообложение;

- Финансы Союза (собственные ресурсы, многолетняя финансовая рамка);

- Гармонизация в области социального обеспечения и социальной защиты;

- Определенные положения в области юстиции и внутренних дел (европейский прокурор, семейное право, оперативное полицейское сотрудничество и т.д.);

- Статья о гибкости (352 TFEU), позволяющая Союзу для достижения определенной цели действовать при отсутствии конкретного правового базиса в договорах;

- Общая внешняя политика и политика безопасности, за исключением некоторых четко определенных случаев;

- Общая политика по безопасности и обороне, за исключением установления постоянного структурированного сотрудничества;

- Гражданство (предоставление новых прав европейским гражданам, анти-дискриминационные меры);

- Определенные институциональные вопросы (избирательная система и структура парламента, определенные назначения, конституирование Комитета Регионов и Европейского Экономического и Социального комитета; количество мест в институциях, официальные языки, пересмотр договоров, включая переходные параграфы и т.д.). 
принимаются положительными голосами девяти его членов, тогда как решения по всем другим вопросам принимаются девятью голосами, включая все голоса постоянных членов. Это означает, что пять постоянных членов, представляющих 2.58 процента от числа всех стран-членов, имеют право на вето на все решения Совета Безопасности по всем непроцедурным вопросам. ${ }^{4}$

Принципы принятия решений в НАТО основаны на консенсусе и таким образом представляют принципы равенства и солидарности всех стран-членов Альянса. Все члены Североатлантического Совета (CAC) имеют не только равное право выражать свои взгляды, но и равную долю в консенсусе, на котором эти решения основываются. Решения согласовываются на основе единодушия и общего согласия. Нет никакого голосования или решения, принимаемого большинством. Это означает, что политики, принимаемые САС, поддерживаются и являются выражением коллективной воли всех суверенных государств, которые являются членами Альянса и приняты ими. 5

\section{Основные вызовы перед НАТО}

Сейчас НАТО сталкивается с широким спектром напряжений внутри и между его членами. Тогда как характер этих напряжений варьирует на обширной территории организации (которая простирается от Тихоокеанского побережья Соединенных Штатов и Канады до восточных границ Турции), существуют и некоторые общие вызовы. Как НАТО может справиться с напряженностью, порожденной политическими вызовами внутри его стран-членов? Как НАТО может обеспечить баланс между гражданской и военной ролью в ситуациях, требующих вмешательства? И как организация, созданная заниматься биполярной реальностью Холодной войны, сможет найти новую роль и новую идентичность для себя в эпоху после окончания Холодной войны? Одна из возможностей найти ответ на эти вопросы состоит в исследовании того, что НАТО в действительности делает в сотрудничестве с ООН и EC.

4 Смотри Главу V Устава ООН, на http://www.un.org/en/documents/charter/chapter5.shtml. Член 23 Главы V определяет конституирование Совета Безопасности. Он конкретизирует, что в добавление к пяти постоянным членам, Общее собрание ООН должно выбрать десять других членов Объединенных Наций непостоянными членами Совета Безопасности, учитывая вклад членов в поддержание международного мира и безопасности и в достижении других целей организации, а также равномерность географического распределения. Эти непостоянные члены избираются сроком на два года. Член, срок которого заканчивается, не может быть выбран сразу же на второй срок. Каждый член Совета Безопасности имеет одного представителя в Совете.

Статья 27 Главы V обрисовывает процедуры голосования в Совете Безопасности. Каждый член Совета располагает одним голосом. В дополнении к положениям, описанным выше, если член Совета является стороной рассматриваемого спора, то он должен воздержаться от голосования.

5 Смотри http://www.nato.int/cps/en/natolive/topics_49763.htm. 


\section{Официальные отношения между организациями}

Официальные отношения между НАТО и ООН установлены основополагающим документом НАТО, Североатлантическим Договором, который устанавливает механизм доклада НАТО Совету безопасности ООН в случае применения Статьи V (о гарантировании коллективной обороны). ${ }^{6}$

Рабочие отношения между Объединенными Нациями и Альянсом были ограничены во время Холодной войны, но после падения Берлинской стены НАТО внесло свой вклад в принятие большого числа резолюций Совета безопасности ООН. Примеры этого сотрудничества включают:

- Резолюции Совета безопасности ООН, которые дали мандат на операции НАТО на Балканах и в Афганистане, и рамочный документ о тренировочной миссии НАТО в Ираке. ${ }^{7}$

- UNSCR 1325, принятая в октябре 2000 года. Эта резолюция признает непропорционально большое влияние, которое войны и конфликты оказывают на женщин и детей, и подчеркивает тот факт, что женщины в силу исторических причин оставались в стороне от мирных процессов и усилий по

6 Полный текст Североатлантического Договора доступен на www.nato.int/cps/en/natolive/ official_texts_17120.htm. Статья 1 договора гласит, что стороны предпринимают, как требуется Уставом ООН, все необходимые меры разрешить любой международный спор в который они могут быть вовлечены, мирными средствами таким образом, чтобы не подвергать опасности международный мир, безопасность и справедливость, и будут воздерживаться в своих международных отношениях от угрозы силой или использования силы любым способом, который не соответствует целям Объединенных Наций.

Статья 5 устанавливает, что стороны договариваются о том, что вооруженное нападение на одну или несколько стран в Европе или Северной Америке будет считаться нападением на все страны и далее стороны договариваются, что если такое нападение произойдет, каждая из них, упражняя право на индивидуальную или коллективную самооборону, признанное Статьей 51 Устава Объединенных Наций, поможет стране, подвергшейся нападению такими действиями, которые сочтет необходимыми, включая использование вооруженной силы, с тем, чтобы восстановить и поддерживать безопасность в Североатлантическом регионе. О любом таком вооруженном нападении и всех мерах, предпринятых в результате, следует докладывать в Совет Безопасности. Любые вооруженные действия, предпринятые по Статье 5, должны быть прекращены тогда, когда Совет Безопасности предпринял необходимые меры для восстановления и поддержания международного мира и безопасности.

Статья 7 Североатлантического Договора не изменяет положение о том, что основную ответственность за поддержание международного мира и безопасности несет Совет Безопасности ООН.

Статья 12 говорит, что по происшествии десяти лет с момента вступления Договора в силу, или в любое время после этого, стороны могут консультироваться между собой с целью пересмотра Договора, учитывая факторы, влияющие на мир и безопасность в Северо-Атлантическом регионе, и принимая во внимание текущие меры, предпринимаемые Объединенными Нациями.

7 Смотри http://www.nato.int/cps/en/natolive/topics_50321.htm. 
стабилизации. Резолюция призывает к полному и равноправному на всех уровнях участию женщин для решения проблем в спектре от раннего предупреждения конфликтов до послеконфликтного восстановления, мира и безопасности. ${ }^{8}$

- Резолюция Совета Безопасности ООН 1540, впервые устанавливающая юридически обвязывающее обязательство для всех членов ООН, в соответствии с Главой VII Устава ООН, предпринимать и применять эффективные меры против распространения оружия массового уничтожения, средств его доставки и связанных с ними материалов. ${ }^{9}$

- Резолюция Совета Безопасности OOH UNSCR 1973, одобренная в марте 2011, которая призывает к прекращению огня, полному прекращению насилия, всех атак и репрессий против гражданских лиц в Ливии (мандат закончился 31 октября 2011). ${ }^{10}$ Значение этой резолюции и ангажемент HАТО основывается на доктрине Ответственности Защищать (Responsibility to Protect - R2P), принцип, согласно которому суверенные государства по отдельности, и международная общность в целом, несут ответственность за защиту гражданских лиц от массовых жестокостей.

ЕС разработал документ о сотрудничестве с НАТО, который направлен на увеличение его прозрачности и потенциалов. ${ }^{11}$ Переговоры по этому документу заняли почти три года и были финализированы в декабре 2002. Он включает следующие элементы:

- Договоренности Берлин+ об использовании Европейским Союзом материальных средств и потенциалов НАТО;

- Договоренности о Стратегическом Партнерстве НАТО-ЕС (выдвинутые Декларацией ЕС-НАТО по Европейской Политике по Безопасности и Обороне (ЕПБО) и в обмене письмами между Генеральными Секретарями);

- Договоренности в Документе по применению из Ниццы относительно участия европейских союзников - нечленов ЕС в ЕПБО.

Несмотря на дальнейшее признание преимуществ близкого сотрудничества НАТО-ЕС Группой Экспертов по Новой Стратегической Концепции для НАТО ${ }^{12}$ в

8 Смотри http://www.nato.int/cps/en/natolive/topics_56984.htm.

9 Смотри http://www.state.gov/t/isn/c18943.htm.

10 Смотри http://www.cfr.org/libya/un-security-council-resolution-1973-libya/p24426.

11 Can Buharali, EDAM Board Member, "Better NATO-EU Relations Require More Sincerity," Discussion Paper Series 2010/1, Centre for Economics and Foreign Policy Studies (EDAM), supported by the German Marshall Fund of the United States (GMF) (January 2010); доступно на www.gmfus.org/galleries/ct_publication_attachments/NATOgmfedamNATOpaper.pdf.

12 "NATO 2020: Assured Security; Dynamic Engagement - Analysis and Recommendations," of the Group of Experts on a New Strategic Concept for NATO, 17 Мау 2010; доступно на www.nato.int/cps/en/natolive/official_texts_63654.htm?selectedLocale=en. В 1990-х основной целью НАТО (вместе с Европейским Союзом) была консолидация целостной и свободной 
мае 2010, заявления об укреплении взаимодействия глав государств и правительств в Декларации Лиссабонского Саммита в ноябре $2010,{ }^{13}$ создание новой Стратегической концепции НАТО, и призыв Генерального Секретаря НАТО интенсифицировать практическое сотрудничество НАТО и ЕС, ${ }^{14}$ все официальное взаимодействие между НАТО и ЕС по потенциалам строго канализировано через Группу НАТОЕC. Эта группа работает по определенному списку дискуссионных вопросов, который предварительно взаимно согласован между представителями НАТО и ЕС; действительное взаимодействие практически ограничено до обмена на рабочем уровне между администрациями.

Хотя принятия Кипра в члены ЕС в 2004 можно считать основной причиной для ограниченного сотрудничества между НАТО и ЕС, вследствии проблем, которые оно создает, в частности члену НАТО Турции, существуют и другие причины, из-за которых сотрудничество часто сталкивается с проблемами. Такой причиной может быть желание ЕС войти в сферу безопасности и обороны, которая не была традиционной среди первоначальных задач ЕС, и так сложилось исторически, что она не была областью, за которую несет ответственность Европейский Союз. Этим шагом реципрочные отношения и роли как ЕС, так и НАТО должны быть определены заново, особенно с учетом очень тонкого различия между их концепциями защиты и обороны.

Стоит отметить, что по-настоящему единственной совместной операцией НАТО-ЕС была операция «Алтеа» в Боснии и Герцеговине, начавшаяся в 2004. Такой уровень взаимодействия не был достигнут в других случаях, когда сотрудничество не считалось императивом. Следовательно, сегодня обе организации сотрудничают не полностью, даже тогда, когда работают бок о бок в одном и том же оперативном театре в Косово (KFOR и EULEX), Афганистане (ISAF и EUPOL), и Аденском заливе в Сомали (Океанский Щит и ATALANTA).

Европы. Впервые за время своего существования НАТО предприняло военные действия, чтобы положить конец этническим чисткам на Балканах. Конец Холодной войны позволил альянсу установить партнерские отношения с бывшими противниками, включая Россию, и принять новых членов, которые приобщились к демократическим ценностям и которые могли внести свой вклад в коллективную безопасность НАТО. В результате Европа стала более демократичной, объединенной и мирной, чем когда бы то ни было.

13

«Стратегическая концепция об обороне и безопасности членов Организации Североатлантического Договора», принятая Главами государств и правительств в Лиссабоне, 19 ноября 2010; доступна на www.nato.int/cps/en/natolive/events_66529.htm. Эта концепция заявляет, что государства, членующие в НАТО, должны, в числе прочего, укреплять стратегическое партнерство с ЕС в духе взаимного доверия, прозрачности и уважения автономии и институциональной целостности обеих организаций; усиливать практическое сотрудничество в операциях целого спектра кризисов, от координированного планирования до взаимной поддержке на месте; расширять политические консультации с тем, чтобы включить все сферы взаимного интереса, с целью вырабатывать общие оценки и точки зрения; и полнее сотрудничать в развитии потенциалов, минимизации дублирования и максимизации ценовой эффективности.

14 CM. www.nato.int/cps/en/SID-5BAFFF96-B6D80BDD/natolive/opinions_70400.htm. 
С 2003 ЕС провел более двадцати военных и гражданских операций. И среди них только две были типа Берлин+, которые использовали материальные ресурсы и потенциалы НАТО. Есть как минимум два объяснения малого числа Берлин+ операций. Первое, эти операции ЕС были ограниченного масштаба и следовательно, все необходимые ресурсы могли быть обеспечены ЕС. В любом случае, в большинстве этих операций военный компонент был ограничен. Второе, имея в виду трудности, связанные с отношениями НАТО-ЕС, Европейский Союз стремился развить потенциалы, которые позволят ему действовать автономно так быстро, как это будет возможно. ${ }^{15}$

\section{Укрепляющие друг друга взаимно институции: следующий шаг к дополне- нию ролей}

Взаимное укрепление трех международных институций-ООН, ЕС и НАТО-обуславливается не только различиями и дополняющимися функциями их мандатов, но также и тем фактом, что в этих организациях есть общие члены. НАТО и ЕС уже имеют двадцать один и, возможно в скором будущем, двадцать шесть общих членов, а все члены обеих организаций являются также членами ООН.

Другим аспектом комплементарности этих трех институций является направление их расширения путем принятия новых членов в НАТО и в ЕС. Направление расширения Европейского союза (ввиду текущих финансовых трудностей в еврозоне) сфокусировано на ассимиляции остающихся Балканских стран-Хорватии, Македонии и Черногории-и на него бросает тень спор между БЮРМ и Грецией ${ }^{16} \mathrm{O}$ названии Бывшей Югославской Республики Македония (БЮРМ). ${ }^{17}$

Возможное принятие Исландии в Союз будет иметь незначительное влияние на ЕС в целом. Принятие затормаживается чувствительными дискуссиями о защите агрокультур, рыболовства и китоловства, хотя, похоже, эти проблемы могут быть решены в ближайшем будущем. ${ }^{18}$ Самым большим вызовом остается возможное принятие Турции, перспектива, к которой ЕС, кажется, просто не готов. ЕС считает, что принятие Турции будет отличаться от предыдущих случаев расширения из-за комплексного эффекта: турецкого населения, географического размера и расположения, экономического, оборонного и военного потенциалов, также и из-за куль-

15 Buharali, "Better NATO-EU Relations Require More Sincerity."

16 См. www.euractiv.com/enlargement/eu-macedonia-relations-linksdossier-329923. Статус кандидата на членство в ЕС был предоставлен в декабре 2005, при председательстве Объединенного Королевства. Пока БЮРМ не успела открыть переговоры ни по одной из глав критериев вследствии вето Греции из-за нерешенных проблем с названием республики.

17 Turkey recognizes the Republic of Macedonia with its constitutional name.

18 Смотри www.europarl.europa.eu/news/nl/pressroom/content/20110318IPR15863/html/MEPswelcome-Iceland's-progress-towards-EU-membership. 
турных и религиозных особенностей страны. ${ }^{19}$ Переговоры о присоединении между ЕС и Турцией приостановлены с $2008 .^{20}$

Основные направления расширения НАТО следуют несколько иному курсу:

- Принятие остававшихся балканских наций (Босния и Герцеговина, БЮРМ, Молдова, Черногория, Сербия);

- Интеграция европейских государств, которые еще не являются частью Альянса (Австрия, Финляндия, Швеция, Швейцария, Ирландия);

- Укрепление сотрудничества НАТО с Россией;

- Принятие бывших советских республик (Грузия, Казахстан, Киргизская Республика, Таджикистан, Туркменистан, Украина, Узбекистан).

Интересным резюме следующих шагов к этим комплементарным ролям является «Исследование о расширении НАТО», датированное 3 сентября 1995 (доступно на сайте НАТО), которое рассматривает процесс расширения НАТО как дополняющий расширение Европейского Союза параллельный процесс, который вносит значительный вклад в расширение безопасности и стабильности в Европе и распространяющий их на новые демократии на Востоке. ${ }^{21}$

19 Commission of the European Communities, Brussels, 6 October 2004, Sec 1202; Commission Staff Working Document on Issues Arising from Turkey's Membership (Com 656 final).

${ }^{20}$ См. http://ec.europa.eu/enlargement/candidate-countries/turkey/eu_turkey_relations_en.htm.

21 См. http://www.nato.int/cps/en/natolive/official_texts_24733.htm. Исследование о расширении НАТО (3 сентября 1995) наметило несколько принципов расширения, начиная с того, что принятие новых членов должно помогать утверждению целей и принципов Устава $\mathrm{OOH}$, защите свободы, общего наследства и цивилизации всех стран-членов Альянса и их народов, целей, основанных на принципах демократии, индивидуальной свободы и верховенстве закона. Новые члены должны следовать этим принципам.

Расширение должно происходить в соответствии с положениями Статьи 10 Североатлантического Договора, которая гласит, что «стороны при единодушном согласии могут пригласить любую другую европейскую страну, которая согласна с принципами этого Договора и может внести вклад в безопасность Североатлантического региона, присоединиться к этому Договору». В дополнении расширение предполагает, что новые члены будут пользоваться всеми правами и выполнять все обязанности согласно Вашингтонскому Договору; будут принимать и следовать принципам, политике и процедурам, воспринятыми всеми членами Альянса; укреплять эффективность и единство Альянса; сохранять политическую и военную готовность Альянса выполнять свои основные функции по общей обороне, а также предпринимать операции по сохранению мира и других новых миссий.

Ожидается, что новые члены будут частью более широкой архитектуры европейской безопасности, основанной на реальном сотрудничестве во всей Европе. Такая структура не будет угрозой ни для одной страны, а будет служить укреплению стабильности и безопасности всей Европы. От новых членов ожидается, что они и далее будут уважать важную роль инициативы «Партнерство ради мира» (ПрМ), которая помогает готовить заинтересованные страны путем вовлечения их в деятельность ПрМ, к преимуществам и ответственностям возможного членства, и так же служит средством укрепления отноше- 


\section{Комплексный подход к глобальной безопасности}

Согласно Европейской Стратегии Безопасности (ЕСБ) «В отличии от массированных видимых угроз во времена Холодной войны, ни одна из новых угроз [очерченных в ЕСБ] не является чисто военной; и с ней нельзя справиться только военными средствами. Каждая из них требует использования набора разных инструментов». Более того, большинство конфликтов сегодняшнего дня происходят на местах, физически удаленных от европейской или евро-атлантической территории, но многие из них считаются представляющими опасность для населения стран-членов ЕС или НАТО. И Концепция человеческой безопасности, которая принята в $\mathrm{EC},{ }^{22}$ и концепция ООН об «Ответственности защищать» ${ }^{23}$ призывает к интернационализации и глобализации ответственности за предотвращение геноцида и массовой жестокости и к защите потенциальных жертв.

Новая Стратегическая Концепция НАТО, принятая на Лиссабонском саммите в ноябре 2010, подчеркивает, что выводы, сделанные из операций НАТО, показывают, что эффективный кризисный менеджмент требует комплексного подхода, включающего политические, гражданские и военные инструменты. Военные средства, хотя и являются важными, недостаточны сами по себе, чтобы ответить на комплексные вызовы, направленные к Евро-атлантической и международной безопасности. Союзные лидеры на Лиссабонском саммите договорились увеличить вклад НАТО в комплексный подход к менеджменту кризисов как часть усилий международной общности и усовершенствовать способности НАТО содействовать стабилизации и реконструкции. ${ }^{24}$

Итак, изменения в трех измерениях военных конфликтов-комбинированный характер угроз, удаленное географическое положение конфликтов и признание интертерриториальной ответственности за защиту,一являются хорошо идентифицированными и узнаваемыми. Ответом на вызовы, которые приносят эти изменения,

ний со странами-партнерами, которые вряд ли присоединятся к Альянсу в ближайшем времени или вообще не присоединятся. И последнее, от новых членов НАТО ожидается, что они дополнят расширение ЕС как параллельного процесса, который также будет содействовать расширению безопасности и стабилизации новых демократий на Востоке.

22 Mary Kaldor, Mary Martin, and Sabine Selchow, "Human Security: A New Strategic Narrative for Europe," International Affairs 83:2 (2007): 273-88. «Принцип безопасности человека, может быть, является единственным способом заполнить то, что может быть определено как пробел в безопасности. Конвенциональные военные подходы, похоже, не работают в таких местах как Ирак, или Афганистан, или Ливан. Миллионы людей в больших районах Африки, Ближнего Востока, на Балканах, в Центральной Азии и на Кавказе проживают в состоянии повышенной опасности. Неспособность наших институций справиться с проблемами глобальной небезопасности существенно ослабляет их легитимность».

23 Alex J. Bellamy, "The Responsibility to Protect - Five Years On," Ethics and International Affairs 24:2 (Summer 2010): 143-69.

24 NATO, “A 'Comprehensive Approach' to Crisis Management" (updated 21 March 2012); доступно на http://www.nato.int/cps/en/natolive/topics_51633.htm. 
является принятие комплексного подхода, который будет включать все международные факторы, в том числе ООН, ЕС и НАТО.

У НАТО есть преимущество наличия ясности относительно оснований его существования, напрямую ссылающихся на принципы демократии и индивидуальной свободы и делающие упор на принципы реализации через возможности коллективной обороны. Действительно, НАТО можно рассматривать как пример региональной реализации принципов ООН с добавлением политического контекста демократии и преимущества от строительства организации на основе многочисленных общих для стран-членов исторических и экономических характеристик. Как пример, НАТО может служить платформой для реализации политики и консультаций, поскольку количество общих с ЕС членов равняется двадцати одному. В то же время, НАТО в состоянии оставаться четко сфокусированным на сохранении мира и безопасности для своих членов.

Хотя принципы принятия решений в НАТО основаны на консенсусе, положение, что НАТО требуется одобрение в форме резолюции Совета Безопасности Объединенных Наций, чтобы задействовать свои операции de facto, ставит миссии Альянса под надзор наций, которые не являются частью НАТО, включая Русскую федерацию (партнер НАТО) и Китайскую Народную Республику. Это положение порождает необходимость обширных консультаций насчет любой операции Альянса, прежде чем будет получен мандат на ее проведение, таким образом, подтверждается ключевая роль стран не-членов НАТО при развитии миссии и релевантности Альянса. Вследствии увеличения ее региональной роли, Турция, вместе с Китаем и Россией, превратилась в третьего ключевого партнера в дальнейшем развитии стратегического партнерства между ООН, ЕС и НАТО.

Призыв Генерального Секретаря Объединенных Наций Бан Ки-Муна к $\mathrm{OOH}$ преодолеть пропасть между его высокой риторикой и часто не столь высокими результатами, не может быть выполнен ни одной международной организацией самостоятельно. Комплементарные функции ООН, ЕС и НАТО должны и далее использоваться в полной мере, в особенности в случае взаимодействия НАТО-ЕС, в прагматической реализации принятых на высоком уровне политических решений. 


\section{Литература}

Bellamy, Alex J. "The Responsibility to Protect - Five Years On." Ethics and International Affairs 24, no. 2 (2010): 143-69.

Buharali, Can. "Better NATO-EU Relations Require More Sincerity." In Discussion Paper Series 2010/1. Centre for Economics and Foreign Policy Studies (EDAM), 2010.

Kaldor, Mary, Mary Martin, and Sabine Selchow. "Human Security: A New Strategic Narrative for Europe." International Affairs 83, no. 2 (2007): 273-88.

NATO 2020: Assured Security; Dynamic Engagement - Analysis and Recommendations., 2010.

NATO. Strategic Concept for the Defence and Security of the Members of the North Atlantic Treaty Organisation. Heads of State and Government in Lisbon, 2010. 